\title{
ESTIMATION OF BORIC ACID IN FOODS.
}

BY L. DE KoNINGH.

Received November $13,1896$.

T $\mathrm{HE}$ estimation of boric acid, at one time very troublesome, has become quite an easy matter since the discovery that it may be accurately titrated in presence of glycerol with phenolphthalein as indicator. To apply the process to articles of food, (and I will confine myself for the present to milk and uncooked eggs,) some few precautions must, however, be taken.

Boric acid is seldom used alone, but mostly in admixture with borax, a mixture of three parts of the acid with one part of ground borax, constituting the article known as glacialine. In practice it is, however, in my opinion, not necessary to make a distinction between the acid and its sodium salt, as both are no doubt equally harmless in small quantities; but if the amount of either reaches one per cent. or more the time has come for a protest.

When testing uncooked eggs (the entire contents beaten up) for boric acid, I take five grams of the sample, add one drop of sodium hydroxide ( $I: I$ ), dry, and finally incinerate. The char is then powdered, boiled with water, and the residual black mass again burnt. The ash is also boiled with water and the two solutions are united. The liquid is now faintly colored by methyl orange and tenth-normal sulphuric acid is added until a faint pink is obtained. The solution is now boiled for a minute to expel carbon dioxide, cooled, mixed with one-half of its bulk of glycerol, and titrated with tenth-normal sodium hydroxide, with phenolphthalein as indicator. Althongh it is now admitted that in presence of glycerol the amount of acid may be calculated from the number of cubic centimeters of sodium hydroxide used, I prefer to check my sodium hydroxide with pure crystallized boric acid, using about the same quantity as present in the sample, and mixing this up with exactly the same amount of glycerol and water. Working in this manner the estimation of boric acid is, as regards accuracy, second to none.

It must, however, be remembered that eggs contain a small quantity of alkaline phosphates, and that phosphoric acid behaves somewhat like the boric acid. A method of removing this acid has already been proposed and is based on the insolu- 
bility of calcium phosphate and the comparatively large solubility of the borate. I find, however, that in uncooked eggs there is just enough phosphoric acid to account for three cc. tenth-normal sodium hydroxide, when working on five grams of sample, so I now propose to deduct three cc. of sodium hydroxide from the number of cubic centimeters taken by the sample. I scarcely need point out the necessity of proving the acid by the alcohol test. As a rule the presence may be ascertained by simply stirring some of the sample with a drop of sulphuric acid and a little spirits of wine and then setting fire to it.

When dealing with milk I allow one cc. of sodium hydroxide for every ten grams of the sample. If the amount of acid is, as usual, very small, no particular accuracy can be claimed for the process; but if present in larger and, consequently harmful quantity, the results are all that may be desired.

LONDON, ENG., JUNE, 1896.

\section{A STUDY OF THE CLARIFICATION OF SUGAR CANE JUICE.'}

\section{By J. I. BEESON.}

Receiverl December 3, 1895

$\prod^{H}$ HE clarification of the cane juice, so important a factor in the manufacture of sugar, is practically the same in method as that in use by the planters of Louisiana one hundred years ago. The method consists in the addition of slaked lime or milk of lime to the cold juice until neutrality or slight alkalinity is reached; then the temperature of the mass is raised nearly to boiling, when a coagulum forms and is carried to the surface by the upward motion of the liquid, and there forms a thick dark green scum called "the blanket." This is remored by skimming, and calcium superphosphate solution (called clariphos), is added until the juice begins to brighten in color. The method is, in the main, an empirical one, the nature of the bodies removed and the chemical changes involved therein not being understood. The practical sugar boiler has virtually no facts to guide him in this important branch of his work. It was therefore the object of this investigation to compare the juice expressed by the mill with that obtained from the same large sample of cane obtained by

1 This work was done in the laboratory of the Audubon Sugar School. New Otleans. which institution was discontinued last July. 